\title{
Chronic Illness
}

http://chi.sagepub.com/

\section{Health work by older people with chronic illness: how much time does it take?} Laurann Yen, Ian S McRae, Tanisha Jowsey, James Gillespie, Paul Dugdale, Michelle Banfield,

Paul Mathews and Marjan Kljakovic

Chronic IIIness published online 5 March 2013

DOI: $10.1177 / 1742395313476720$

The online version of this article can be found at:

http://chi.sagepub.com/content/early/2013/03/05/1742395313476720

\author{
Published by: \\ (SAGE \\ http://www.sagepublications.com
}

Additional services and information for Chronic IIIness can be found at:

Email Alerts: http://chi.sagepub.com/cgi/alerts

Subscriptions: http://chi.sagepub.com/subscriptions

Reprints: http://www.sagepub.com/journalsReprints.nav

Permissions: http://www.sagepub.com/journalsPermissions.nav

>> OnlineFirst Version of Record - Mar 5, 2013

What is This? 


\title{
Health work by older people with chronic illness: how much time does it take?
}

Chronic Illness $0(0) 1-15$

(C) The Author(s) 2013

Reprints and permissions: sagepub.co.uk/journalsPermissions.nav DOI: I0.1 I77/I7423953।3476720 chi.sagepub.com (3)AGE

\author{
Laurann Yen,' Ian S McRae,' Tanisha Jowsey, ' \\ James Gillespie, ${ }^{2}$ Paul Dugdale, ${ }^{3,4}$ \\ Michelle Banfield,',2 Paul Matthews' \\ and Marjan Kljakovic ${ }^{4}$
}

\begin{abstract}
Purpose: People living with chronic illness report spending a lot of time managing their health, attempting to balance the demands of their illness/es with other activities. This study was designed to measure the time older people with chronic illness spend on specific health-related activities. Key methods: Data were collected in 2010 using a national survey of people aged 50 years and over selected from the membership of National Seniors Australia, the Diabetes Services Scheme and The Lung Foundation. Respondents provided recall data on time used for personal health care, non-clinical health activity; and health service interactions.

Main results: While most people with a chronic illness spend on average less than 30 minutes a day on health-related activities, the highest decile of respondents averaged at least 2 hours each day. People with COPD report the highest expenditure of time. The greatest amount of time was spent on daily personal health care activities.

Main conclusion: For a minority of people with chronic illness, time demands for health-related activities can be so great that other activities must be affected. Some time demands are amenable to system interventions that would result in a more patient-centered organisation of care.
\end{abstract}

\section{Keywords}

Time, self-management, chronic illness, complexity, work

Received 25 November 20I2; accepted 9 January 2013

\footnotetext{
'Australian Primary Health Care Research Institute, The Australian National University, Australia

${ }^{2}$ Master of Health Policy, Sydney School of Public Health, Sydney Medical School, The University of Sydney, Australia ${ }^{3}$ Centre for Health Stewardship, The Australian National University, Australia
}

${ }^{4}$ Academic Unit of General Practice, ANU Medical School,
Canberra Hospital, The Australian National University, Australia

Corresponding author:

Laurann Yen, Australian Primary Health Care Research Institute, lan Potter House, Corner of Marcus Clarke and Gordon Streets, Australian National University, ACTON 0200 ACT, Australia.

Email: Laurann.Yen@anu.edu.au 


\section{Introduction}

It has become a truism in developed countries that managing chronic ill health and multi-morbidity are among the foremost challenges facing their health care systems. Accordingly, a number of policy reviews have sought to provide systematic guidance on strategy and service delivery ${ }^{1-3}$ to respond to the impact of the challenges of morbidity, mortality, and economic costs. A common response to these reviews has been new strategies for integrated care, incorporating a range of measures to support selfcare, as exemplified by Wagner's Chronic Care Model. ${ }^{4}$

In practice, any chronic care model must incorporate a substantial element of selfcare since living with chronic illness is an everyday affair that people and their families and communities must manage. However, there is a relative dearth of empirical studies examining the nature and quantity of selfcare across groups of people with chronic illness and with multiple conditions. As a result, this activity is rarely counted in the health literature as part of the cost of health care, or incorporated into chronic care management models.

Corbin and Straus (p. 226) ${ }^{5}$ identify three types of work associated with managing chronic illness at home, including illness work that 'consists of regimen work, crisis prevention and management, symptom management and diagnostic related work.'

Using another approach, May et al. ${ }^{6}$ have recognised that people with chronic illness are often burdened by the demands of their treatment, to the point where they may be overwhelmed by both the scale and the complexity of the tasks that fall to them in managing their health. They suggest that it is within the remit of the health system to develop 'minimally disruptive medicine' so that people with chronic illness are enabled, through the varied course of their illness, to manage their health in the way that best suits their needs.

Rogers et al. (p. 3$)^{7,8}$ have identified that the construct of the work of chronic illness (among other action oriented constructs) is 'under-identified and tested empirically and are, thus, insufficiently specific about the contexts, resources, practices and networks that fall within the ambit of "work".

Evidence from qualitative studies, including our own, ${ }^{8,9}$ suggests that the work associated with the management of chronic illnesses is often perceived as a significant 'time burden' by people with chronic illness and their carers. It is not known, however, how much time people who are chronically ill spend managing their health and on what particular activities, which this study addresses.

Russell,${ }^{10}$ using data from the US Bureau of Labor Studies American Time Use Survey, reported that the average time spent in the previous 24-hour period by adult Americans reporting that they had spent time on health-related activities was $108 \mathrm{~min}$. Of those reporting a particular activity in the period, mean times spent were $86 \mathrm{~min}$ for personal care, $123 \mathrm{~min}$ for medical and care services and $114 \mathrm{~min}$ on sports, exercise and recreation. Russell ${ }^{11}$ also reported from the American Time Use Survey data that for those attending medical and care services on a designated day, the mean time for travel was $35 \mathrm{~min}$, for waiting was $42 \mathrm{~min}$ and $74 \mathrm{~min}$ for actually receiving services. Her study showed that people in rural areas spent more time attending care than urban residents, some of which may have been related to travel time.

A number of other US research studies have identified time spent on health-related activities by people with a chronic illness. Ettner $^{12}$ looked at the time spent by respondents from different socio economic groups with diabetes mellitus in managing care and Safford ${ }^{13}$ showed that following diagnosis of diabetes, participants spent additional time on a range of health-related 
activities, such as medication management and foot care. Russell ${ }^{14}$ used a convenience sample of diabetes educators to estimate that $2 \mathrm{~h}$ a day is required to manage diabetes. Most Australian literature ${ }^{15-18}$ has focused on time use from a carer perspective, using information from the Australian Bureau of Statistics Household Survey. In the only Australian study we identified that specifically addressed time use on health-related activities for people with a chronic condition, McKenna ${ }^{19}$ found that people living in the community following a stroke spent less than 30 min a day on their health care. Review of these findings suggested a need for more detailed and systematic examination of the time use of people with chronic illness.

The current study was conceived to redress an imbalance in the research literature and to survey this largely hidden aspect of health care. We used a national survey of older Australians to find out how much time older people, particularly those with chronic illness, spend on health-related activities.

\section{Methods}

\section{Survey design}

A survey titled 'How much work is involved in looking after your health?' was designed to collect data in four sections; demographics, health services use, time spent by individuals on health-related activities and time spent similarly by carers.

Data were collected on standard demographic variables, the respondent's perceptions of their own health (SF12 and EQ5D, both standard measures of self-assessed health) and the chronic illnesses with which they had been diagnosed.

A series of questions related to health services use, including type and number of health professionals consulted in the previous 3 months and attendance at Emergency Departments in the last 12 months. Three multipart questions were designed to obtain information about time use in hours and minutes on personal, everyday care; nonclinical health-related time; and time required for accessing health services (see Appendix). An aligned set of questions was asked of respondents who were also carers in relation to their time spent caring.

The questionnaire was piloted with 28 people from an earlier survey who had indicated an interest in being involved in further research. Pilot respondents were asked in addition to comment on the time taken to complete the survey, its general relevance and interest and the nature of the questions. The questionnaire was modified, and re-tested with a group of members of a local health service consumer network. The survey was mailed to selected individuals (as below), with the option to complete it on line using Survey Monkey ${ }^{\circledR}$, a proprietary survey tool, or to complete the form and return it by prepaid post.

\section{Sample}

Participants were selected using stratified sampling from members of three organisations: National Seniors Australia, (a nonprofit organisation representing Australians aged 50 and over with 285,000 members and broadly representative of the older Australian community), the National Diabetes Services Scheme (a government funded service delivering subsidised diabetes supplies, information and support for people with diabetes with 280,000 registrants aged 50 and over) and the Australian Lung Foundation (a non-profit, advocacy, education, fund raising and support organisation with over 14,000 members).

A sample of 5000 members was drawn from the NSA members, stratified by State, and age with an oversampling of older members to increase the proportions with chronic illness. A sample of 2500 registrants aged 50 years or over was drawn from the National Diabetes Services Scheme (NDSS) 
register, stratified by State, age and gender with no oversampling as the scheme operates specifically to subsidise costs for persons with diabetes. All 3062 members of the Australian Lung Foundation with COPD were surveyed. These samples are referred to as Seniors, Diabetes and COPD, respectively throughout.

\section{Data collection and analysis}

Data were entered into SPSS files for analysis. On-line responses were merged electronically. Analysis was undertaken using SPSS Version 19 (Somers, NY, USA) and Stata 9 (College Station, TX, USA).

Descriptive analysis was used to assess in our three sub-samples:

- overall health care time use,

- time use in relation to basic demographics,

- time use in relation to numbers of illnesses and self-assessed overall health,

- time use in relation to particular illnesses (noting that the time is the total time spent by people with these illnesses, but as they may have multiple illnesses, this is not the same as the time required to address that particular illness).

This complex stratified sample structure and the variable response rates meant that separate weighting was needed for each subsample and all estimates provided here are weighted. The three samples were treated separately to give greater analytical clarity. This was at the sacrifice of the power of some comparisons.

\section{Time measurement}

We asked how much time was spent 'on most days' for frequent, regular activities, such as managing and taking medication, and in the last month' for less regular activities, such as shopping for special food, attending support groups, or visiting a doctor. The times reported have been trimmed to remove impossible and implausible values for each component question and for aggregates. Division or multiplication by 30 was used to convert between monthly and daily time use.

The distribution is highly skewed, being truncated at zero, but having a long tail, so medians are more useful than means for most purposes although we report both for completeness. As a major question is which groups face the greatest time demands the 90th percentiles are also discussed to show the time demands experienced by the top $10 \%$ of respondents.

The last component of Q46 relates to taking exercise and stretching. This time has been excluded from this analysis as exercise times were extremely variable, and it was impossible to distinguish exercise taken for strictly health purposes from that with social or other motives.

While almost all respondents spent some time on their health, few participated in all the health-related activities. Estimates of total time therefore include all observations including the relatively small numbers of zeros, but for components of total time we report on both the proportion of respondents undertaking these tasks, and the time spent by those undertaking them. Standard errors are derived using bootstrapping techniques within Stata 9.

\section{Ethics}

Study approval was obtained from the Australian National University Human Research Ethics Committee (Protocol number: 2010/468).

\section{Results}

The survey achieved an overall response rate of $24 \%$, with $17.1 \%$ response in the 
Diabetes sub-sample, $22.2 \%$ in the COPD sub-sample and $28.6 \%$ in the Seniors subsample.

Table 1 shows the basic demographic and health structure of the three sub-samples.

Table 2 shows that the average time demands of health-related activities on older Australians are not trivial, but nor are they extreme for most people. The median times range from 5.2 to $16.6 \mathrm{~h}$ per month the highest group being the COPD sample, which is equivalent to half an hour per day. However, those in the top $10 \%$ of time use in the COPD and Diabetes samples spent 51.4 $62.6 \mathrm{~h}$ per month on their health care equivalent to around $2 \mathrm{~h}$ per day on average, but probably comprising less than this on most days with some days longer with travelling to and attending doctor visits and other health services. Both the COPD sample and the Diabetes sample spent significantly more time on health-related activities than the Seniors sample. The COPD sample spent significantly more than the Diabetes sample at the mean/median although the 90th percentiles of these two samples were not significantly different. While some female estimates are higher than some male estimates, none of the differences was significant.

Table 2, as in most other cases we explored, shows that the 90th percentile time use was of the order of four times the median time use.

Like gender effects, age and region of residence (rurality) effects were relatively small. The education patterns were very unclear and averages and percentiles did not follow any strong patterns. The weak patterns that could be perceived seemed to show more time spent by those with higher qualifications, particularly in the COPD and Diabetes samples. Detailed tables for all the demographics are available from the authors on request.

Figure 1 shows the median and 90th percentile of the time use patterns by age.
The patterns here differed between the samples, with seniors sample showing a small decline in time use with age, the diabetes sample showing an increase in demands with age, but the COPD sample showing a substantial decline with age.

As shown in Table 3, there were strong relationships between time use patterns and employment. In both the Diabetes and the Seniors samples, those employed spent significantly less time on their health care while those not employed (mainly retired) spent more time. The COPD sample showed no significant differences, but the employed sample of 43 respondents was too small to provide stable estimates.

An increased number of chronic conditions was associated with respondents spending more time on their own health care. Figure 2 shows the pattern for the 90th percentile of time use, but similar patterns pertained for the means and medians.

We used the Seniors sample, which broadly represents the overall community, to compare time use between respondents with particular chronic conditions (Table 4), and considered the time use patterns reported by respondents with diabetes, heart conditions, arthritis and COPD. We found that the median time was highest for the people with COPD, but that the means and 90th percentiles showed few differences between the conditions. The time spent by the highest decile for each of these conditions was similar at around 45 to $55 \mathrm{~h}$ per month. Half of those with COPD faced $20 \mathrm{~h}$ or more per month time commitment while the higher time use half of those with the other identified conditions spent around $10 \mathrm{~h}$ per month. The subset of those with COPD who also had diabetes or heart conditions had 90th percentiles were significantly different (with estimates of half an hour longer per day) from the full set of those with COPD alone. 
Table I. Socio-demographic and chronic disease characteristics of samples. (Estimates weighted for non-response)

\begin{tabular}{|c|c|c|c|}
\hline & $\begin{array}{l}\text { Diabetes } \\
\text { sub-sample } \\
(N=427)\end{array}$ & $\begin{array}{l}\text { COPD } \\
\text { sub-sample } \\
(N=68 I)\end{array}$ & $\begin{array}{l}\text { NSA } \\
\text { sub-sample } \\
(N=1432)\end{array}$ \\
\hline & \multicolumn{3}{|c|}{ Percentage of sub-sample population } \\
\hline \multicolumn{4}{|l|}{ Gender } \\
\hline Male & 56.5 & 42.0 & 39.9 \\
\hline Female & 43.5 & 58.0 & 60.1 \\
\hline \multicolumn{4}{|l|}{ Age } \\
\hline Less than 60 years & 25.0 & 11.3 & 26.9 \\
\hline $60-69$ years & 35.6 & 34.4 & 49.5 \\
\hline 70-79 years & 24.8 & 37.5 & 15.3 \\
\hline 80 years and over & 14.7 & 16.9 & 8.2 \\
\hline \multicolumn{4}{|l|}{ Region } \\
\hline Major cities of Australia & 56.7 & 58.5 & 57.6 \\
\hline Inner regional Australia & 29.9 & 32.5 & 27.9 \\
\hline Outer regional Australia & 12.0 & 8.5 & 11.3 \\
\hline Remote and very remote Australia & $\mathrm{I} .4$ & 0.5 & 3.2 \\
\hline \multicolumn{4}{|l|}{ Employment } \\
\hline Working & 22.8 & 6.6 & 36.7 \\
\hline Not working & 77.2 & 93.4 & 63.3 \\
\hline \multicolumn{4}{|l|}{ Self-assessed health } \\
\hline Excellent to good health & 61.4 & 27.7 & 83.2 \\
\hline Poor or fair health & 38.7 & 72.3 & 16.8 \\
\hline \multicolumn{4}{|c|}{ Number of chronic conditions ever diagnosed } \\
\hline Zero conditions & 1.4 & 1.0 & 15.9 \\
\hline One conditions & 12.7 & 12.0 & 27.2 \\
\hline Two conditions & 25.1 & 18.3 & 25.8 \\
\hline Three conditions & 21.2 & 18.5 & 14.4 \\
\hline Four conditions & 15.4 & 19.6 & 8.1 \\
\hline Five or more conditions & 24.1 & 30.6 & 8.5 \\
\hline \multicolumn{4}{|l|}{ Conditions ever diagnosed } \\
\hline Cancer & 24.5 & 23.8 & 25.9 \\
\hline Heart disease & 23.9 & 21.3 & 12.7 \\
\hline Hypertension & 60.8 & 42.7 & 41.9 \\
\hline Stroke & 8.9 & 6.0 & 3.0 \\
\hline Diabetes mellitus & 93.6 & $1 \mathrm{l} .4$ & 11.5 \\
\hline Kidney disease & 8.0 & 4.9 & 3.5 \\
\hline Asthma or hay fever & 18.5 & 37.4 & 19.1 \\
\hline $\begin{array}{l}\text { Chronic obstructive } \\
\text { pulmonary disease }\end{array}$ & 5.1 & 89.5 & 3.8 \\
\hline Arthritis & 34.2 & 37.6 & 35.0 \\
\hline Osteoporosis & 9.0 & 30.8 & 10.1 \\
\hline Chronic pain, including back pain & 25.3 & 31.2 & 19.5 \\
\hline Depression or anxiety & 20.4 & 28.0 & 17.4 \\
\hline
\end{tabular}


Table 2. Total time use by gender and sample component

$\begin{array}{lll}\text { Diabetes } & \text { COPD } & \text { Seniors } \\ \text { Hours per month } & (95 \% \text { confidence interval) } & \end{array}$

\section{Male}

Mean

$19.4(16.0-22.8)$

$28.1(24.2-32.2)$

$12.7(11.0-14.3)$

Median

$11.0(8.4-13.8)$

$17.7(14.6-20.8)$

$4.8(4.1-5.6)$

90th percentile

$46.3(33.7-58.8)$

$60.8(48.8-72.7)$

$27.0(22.3-31.8)$

Female

Mean

$22.3(18.0-26.7)$

$28.7(24.5-32.7)$

14.3 (I2.8-15.8)

Median

II.I (7.5-14.7)

16.0 (13.2-18.6)

$5.3(4.7-5.9)$

90th percentile

$62.5(47.7-77.3)$

$63.5(50.2-76.8)$

$38.0(34.0-42.0)$

Total

Mean

$20.6(17.6-23.5)$

$28.3(25.4-31.3)$

$13.7(12.6-14.7)$

Median

II.I (9.1-13.1)

$16.6(14.6-18.4)$

$5.2(4.8-5.6)$

90th percentile

Total includes missing values for gender.

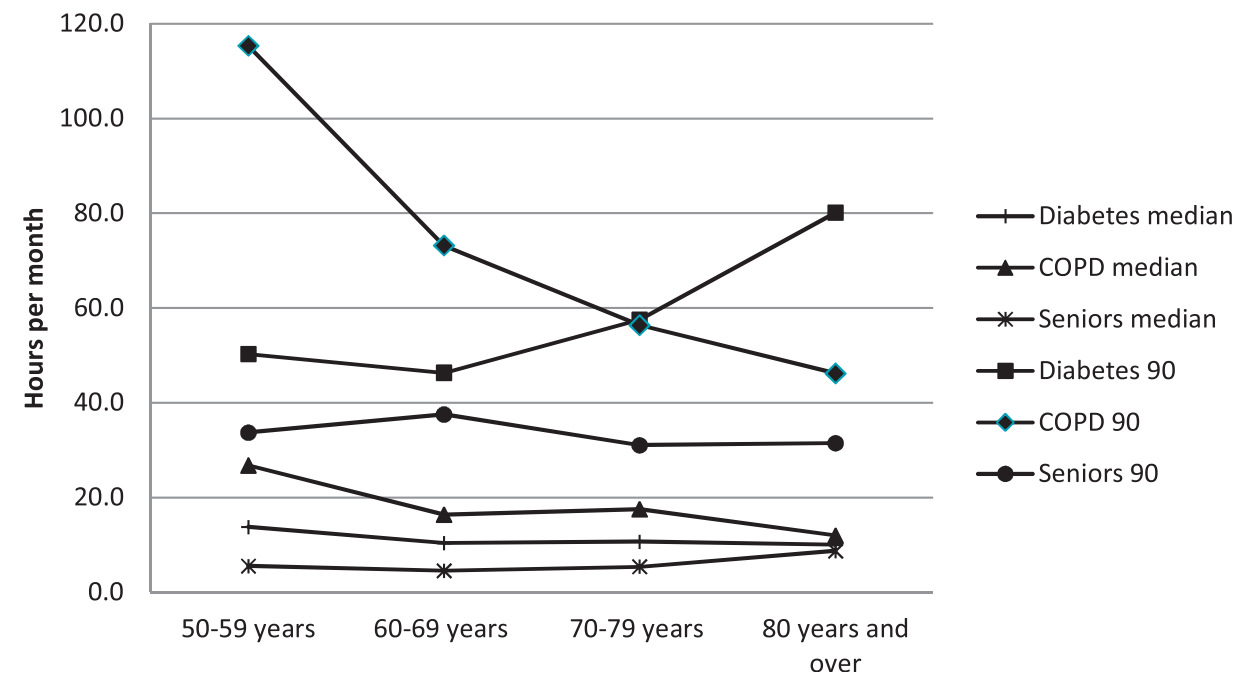

Figure I. Median and 90 th percentile of time spent on own health care by age group.

Table 5 shows the time spent by each sample according to their self-assessed level of health. Those reporting poor health, using either measure, in all the samples spent significantly more time. While in the 'excellent to good health' group the Seniors sample had significantly lower time use than either the Diabetes or the COPD samples, there was no difference between the samples for those rating their health as poor.

\section{Time spent on specific activities}

In attempting to understand what sorts of activities were the most time consuming for people with chronic illness, we looked at the 
Table 3. Total time use by employment and sample component

\begin{tabular}{lccc}
\hline & $\begin{array}{l}\text { Diabetes } \\
\text { Hours per month }(95 \% \text { confidence interval) }\end{array}$ & Seniors \\
\hline Working & & & \\
Mean & $14.4(9.8-18.9)$ & $25.4(16.5-34.2)$ & $11.1(9.2-12.9)$ \\
Median & $5.8(2.1-9.4)$ & $12.3(6.7-17.9)$ & $3.7(2.8-4.5)$ \\
90 th percentile & $31.8(24.8-38.7)$ & $83.0(47.3-118.7)$ & $30.5(26.2-34.8)$ \\
Not working & & & $14.2(12.8-15.6)$ \\
Mean & $21.7(18.4-25.1)$ & $27.8(24.7-30.9)$ & $6.1(5.6-6.6)$ \\
Median & $12.3(10.1-14.4)$ & $17.5(15.1-19.9)$ & $37.5(32.8-42.2)$ \\
90 th percentile & $53.0(40.5-65.5)$ & $60.5(49.5-71.5)$ & $13.7(12.6-14.7)$ \\
Total & & & $5.2(4.8-5.6)$ \\
Mean & $20.6(17.6-23.5)$ & $28.3(25.4-31.3)$ & $34.1(30.7-37.4)$ \\
Median & $11.1(9.1-13.1)$ & $16.6(14.6-18.4)$ & \\
$90 t h$ percentile & $51.4(40.9-61.9)$ & $62.6(53.2-72.0)$ & \\
Total includes observations for those lacking employment history. &
\end{tabular}

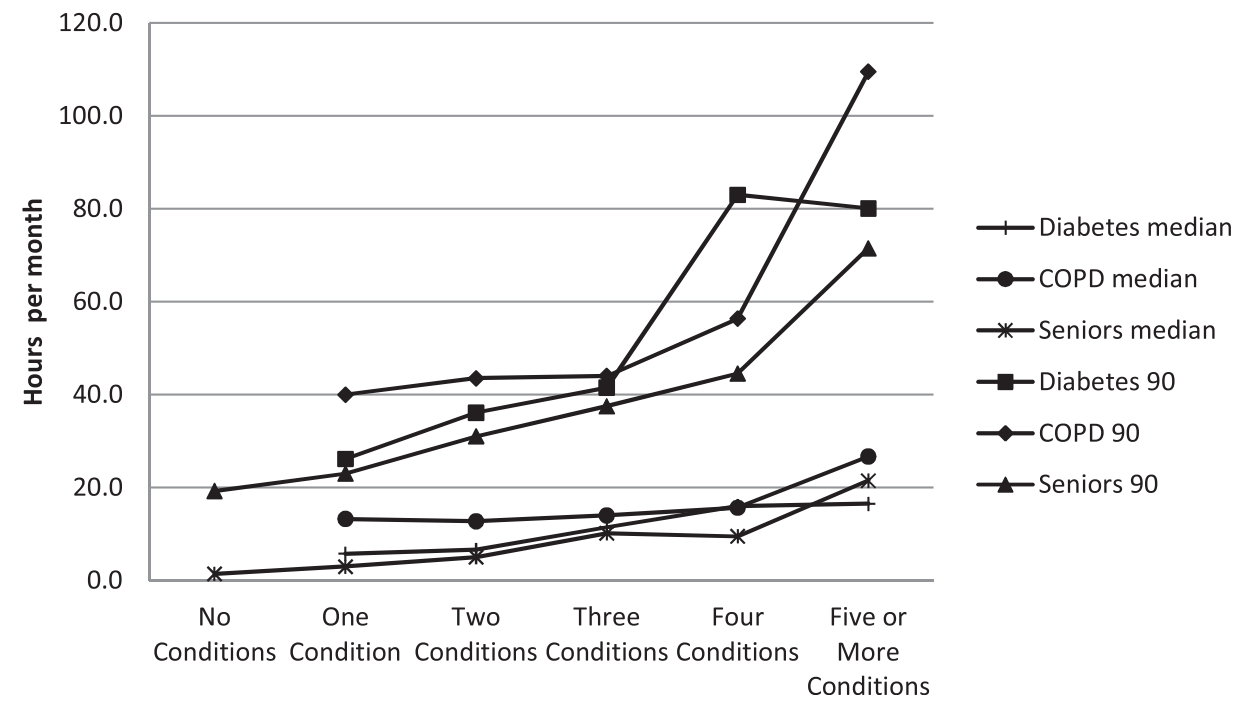

Figure 2. Median and 90 th percentile of total time spent on own health care by number of chronic conditions.

composition of the time spent by respondents, breaking it down within three broad categories of activity:

- daily personal care, consisting of sorting preparing and taking medications, monitoring health, carrying out treatments and preparing special foods (Appendix, Q46)

- non-clinical health-related activity, consisting of shopping for medical or other health-related items, attending support or 
Table 4. Total time for selected chronic conditions for the National Seniors sample

\begin{tabular}{|c|c|c|c|c|}
\hline & \multicolumn{4}{|c|}{ Selected conditions } \\
\hline & Diabetes & Heart conditions & COPD & Arthritis \\
\hline & \multicolumn{4}{|c|}{ Hours per month ( $95 \%$ confidence interval) } \\
\hline Observations & 184 & 245 & 60 & 520 \\
\hline Mean & $25.8(20.7-30.9)$ & $20.5(17.5-23.5)$ & $24.2(|7.0-3| .3)$ & I8.4 (|5.8-2|.0) \\
\hline Median & $12.2(9.7-14.6)$ & $10.8(9.6-12.0)$ & $20.3(13.7-26.8)$ & $7.8(6.8-8.7)$ \\
\hline 90th percentile & $54.5(40.0-69.0)$ & $45.8(36.8-54.7)$ & $54.5(27.6-8 I .4)$ & $42.3(35.9-48.8)$ \\
\hline
\end{tabular}

Table 5. Time use by self-assessed health, all groups

\begin{tabular}{lccc}
\hline & Diabetes & COPD & Seniors \\
\cline { 2 - 4 } & \multicolumn{3}{c}{ Hours per month $(95 \%$ confidence interval) } \\
\hline Excellent to good health & $17.2(14.6-19.7)$ & $19.9(16.1-23.7)$ & $10.5(9.5-11.4)$ \\
Mean & $8.7(6.5-10.8)$ & $9(7.3-10.7)$ & $4(3.6-4.4)$ \\
Median & $43.5(33.5-53.5)$ & $40.5(25.3-55.7)$ & $27(24.0-30.0)$ \\
90th percentile & & & \\
Poor or fair health & $26.1(21.6-30.6)$ & $31.6(28.0-35.3)$ & $29.3(24.1-34.6)$ \\
Mean & $15(11.5-18.5)$ & $19.9(17.6-22.2)$ & $15.3(11.8-18.7)$ \\
Median & $64.5(52.3-76.9)$ & $69(59-79)$ & $73.5(49.4-98.0)$ \\
90th percentile & & & $13.7(12.6-14.7)$ \\
Total & $20.6(17.6-23.5)$ & $28.3(25.4-31.3)$ & $5.2(4.8-5.6)$ \\
Mean & $11.1(9.1-13.1)$ & $16.6(14.6-18.4)$ & $34.1(30.7-37.4)$ \\
Median & $51.4(40.9-61.9)$ & $62.6(53.2-72.0)$ & \\
90 th percentile &
\end{tabular}

rehabilitation activities, and seeking health information (Appendix, Q47)

- health service-related activity, excluding inpatient stays, consisting of organising appointments, travelling, waiting, consulting time and time spent on diagnostic activities, such as blood tests and imaging (Appendix, Q48).

Table 6 shows that the majority of people in all samples spent time on each of these health-related categories. The daily activities were the most common and required the most hours over a month in all samples. This was in part because $5 \mathrm{~min}$ per day was equivalent to two and a half hours per month, whereas a visit to a doctor might only have taken an hour and a half once a month. The samples also show how experiences of time use differed:

- The Seniors sample spent significantly less time on daily and self-management activities than people in the other samples, but those who did spend time on health services-related tasks spent as much time on these as the other samples;

- Significantly fewer in the Seniors sample were engaged in each of the activities than in either the Diabetes or the COPD samples;

- Time use in the COPD sample was almost always higher than in the Diabetes 
Table 6. Structure of time use: median times spent by respondents undertaking activities and percentages of time by activity category ( $95 \%$ confidence intervals in parentheses)

\begin{tabular}{|c|c|c|c|c|c|c|}
\hline & \multicolumn{2}{|l|}{ Diabetes } & \multicolumn{2}{|l|}{ COPD } & \multicolumn{2}{|l|}{ Seniors } \\
\hline & $\begin{array}{l}\text { Percent } \\
\text { using time } \\
\text { on this } \\
\text { category }\end{array}$ & $\begin{array}{l}\text { Median } \\
\text { hours } \\
\text { per month }\end{array}$ & $\begin{array}{l}\text { Percent } \\
\text { using } \\
\text { time on this } \\
\text { category }\end{array}$ & $\begin{array}{l}\text { Median } \\
\text { hours } \\
\text { per month }\end{array}$ & $\begin{array}{l}\text { Percent } \\
\text { using } \\
\text { time on } \\
\text { this } \\
\text { category }\end{array}$ & $\begin{array}{l}\text { Median } \\
\text { hours per } \\
\text { month }\end{array}$ \\
\hline $\begin{array}{l}\text { Personal care activity } \\
\text { undertaken } \\
\text { on most days } \\
\text { (excluding exercise) }\end{array}$ & $\begin{array}{l}91.2 \% \\
(88.3-94.1)\end{array}$ & $\begin{array}{l}7.5 \\
(6.3-8.7)\end{array}$ & $\begin{array}{l}94.5 \% \\
(92.7-96.3)\end{array}$ & $\begin{array}{l}7.5 \\
(6.7-8.3)\end{array}$ & $\begin{array}{l}76.4 \% \\
(74.0-78.7)\end{array}$ & $\begin{array}{l}3.0 \\
(2.5-3.5)\end{array}$ \\
\hline $\begin{array}{l}\text { Non-clinical but } \\
\text { health-related } \\
\text { activities }\end{array}$ & $\begin{array}{l}80.8 \% \\
(76.9-84.8)\end{array}$ & $\begin{array}{l}1.0 \\
(0.76-1.24)\end{array}$ & $\begin{array}{l}84.6 \% \\
(81.5-87.7)\end{array}$ & $\begin{array}{l}2.0 \\
(1.6-2.4)\end{array}$ & $\begin{array}{l}75.2 \% \\
(73.3-77.1)\end{array}$ & $\begin{array}{l}0.7 \\
(0.5-0.8)\end{array}$ \\
\hline $\begin{array}{l}\text { Health service-related } \\
\text { activities }\end{array}$ & $\begin{array}{l}82.4 \% \\
(78.3-86.6)\end{array}$ & $\begin{array}{l}2.2 \\
(1.9-2.5)\end{array}$ & $\begin{array}{l}87.8 \% \\
(85.4-90.3)\end{array}$ & $\begin{array}{l}4.0 \\
(3.3-4.6)\end{array}$ & $\begin{array}{l}76.7 \% \\
(74.8-78.7)\end{array}$ & $\begin{array}{l}2.4 \\
(2.2-2.6)\end{array}$ \\
\hline $\begin{array}{l}\text { Total time excluding } \\
\text { exercise }^{\mathrm{a}}\end{array}$ & $\begin{array}{l}95.1 \% \\
(93.1-97.1)\end{array}$ & $\begin{array}{l}12.25 \\
(10.0-14.5)\end{array}$ & $\begin{array}{l}97.8 \% \\
(96.7-98.8)\end{array}$ & $\begin{array}{l}17.5 \\
(15.5-19.5)\end{array}$ & $\begin{array}{l}92.6 \% \\
(91.4-93.8)\end{array}$ & $\begin{array}{l}6.0 \\
(5.6-6.4)\end{array}$ \\
\hline
\end{tabular}

${ }^{a}$ Note that these values differ from those in previous tables as zeros are included in other tables and excluded from median calculations here.

sample (except time spent by those engaged in daily activities). Most of the differences were significant while the proportions participating were not significantly different.

\section{Discussion}

\section{Summary of main findings}

Some aspects of the time demands of healthrelated activity for older people with chronic illness have been demonstrated by this study. The actual time cost for most respondents was relatively small with the average time spent on health-related activities less than an hour per day. However, the top $10 \%$ of both the COPD and the Diabetes samples spent over $50 \mathrm{~h}$ per month, equivalent to almost $2 \mathrm{~h}$ per day on average on health-related activities. Amongst the Seniors sample, which is broadly representative of older
Australians and includes people with no chronic illnesses, the 90th percentile is $34 \mathrm{~h}$ per month.

Our study found a heterogeneous pattern of time use. We found that the amount of time people spent on their health care was more a function of the number of chronic conditions they reported, than their social or demographic characteristics. The top 10\% of those people with five or more chronic conditions in the COPD sample spent over 3 $h$ per day on average on their health, and those in the Diabetes sample spent a little less at an average of just under $3 \mathrm{~h}$ per day. The top $10 \%$ of those in the Seniors sample with five or more conditions spent more than $2 \mathrm{~h}$ per day on their health. The attempt to isolate patterns associated with individual conditions was complicated by the ubiquity of co-morbidity. However, comparing the diabetes patients in the Diabetes sample with the COPD patients in the COPD sample would suggest that COPD time 
demands are roughly $30 \%$ higher than those of diabetes.

Daily activities take up the majority of the total time, but for the heaviest time users the amount spent on blocks of activity (such as time spent attending health service appointments) was not insubstantial.

\section{Strengths and limitations of the study}

This study is one of few that attempts to measure time spent on health work for older people with chronic illness and provides a base for further research in the field. The overall response rate was low and may have been improved had we followed up nonresponders. Follow up was considered impractical because of the complex requirements of data access with two of the data custodians.

The survey method creates limits for the flexibility of the data, so, for example, our choice of using recall estimates rather than diaries may blur some time distinctions. However, our measures balanced the known bias of inaccurate recall ${ }^{20}$ with the pragmatic measure of a snapshot of time use to minimise the burden on participants. Exclusion of exercise data collected also limited the scope of our analysis. The overall response rate of around $25 \%$ points to a potential for response bias, which might most obviously exclude those facing the most time pressures who do not have the time to address a survey such as this.

This study has only looked at time spent currently on a particular set of healthrelated activities. It does not account for changes in time taken to undertake healthrelated or other everyday activities as illness progresses, such as house work, or gardening, thinking and planning those activities included as 'everyday work' and 'biographical work' by Corbin and Strauss. ${ }^{5}$ One participant in our earlier qualitative study, ${ }^{21}$ for example, described how some tasks that she had been able to "whip through in 20 minutes' now took her several hours because of her lack of stamina and the need to rest after even a brief period of activity. More particularly, our approach 'evens out' the demands, so that while most people average less than $30 \mathrm{~min}$ a day on their health management, this does not help understand the burden, described so well by May et al. ${ }^{6}$ of the often 'lumpy' demands of illness.

\section{How do these findings compare with findings of other research?}

The difference between these findings, and those of Russell, ${ }^{10}$ which initially look similar, is that Russell reports activities undertaken in the previous $24 \mathrm{~h}$ by those engaging in health-related activities. Our study, on the other hand, reports average time use daily, of around $30 \mathrm{~min}$ a day, rising to over $2 \mathrm{~h}$ on average for those in the top $10 \%$. For people with a chronic illness, there are many health-related activities that occur daily. The total time spent on health-related activities over a longer period will be cumulative; and likely to be higher than time use by those with episodic health needs. The results provide some support for the estimates by health professionals that $2 \mathrm{~h}$ a day would be required for management of diabetes, as reported by Russell; ${ }^{14}$ and with Safford's ${ }^{13}$ reports of time spent by people with diabetes on selfcare. However, there is little else in the literature with which to compare these findings. While surveys from a number of countries, ${ }^{22}$ including Australia, US, Canada and many European countries ask about health-related activity, these are generally not reported in relation to chronic illness, nor are distinctions made between the many types of health activity undertaken. 


\section{The implications for research in health services policy and systems}

Health policies in most Western systems encourage patients and their carers to use self-management approaches to remain as healthy as possible, and so to live independently for longer and avoid unnecessary hospital admissions. The findings of this study show that engagement in healthrelated activities comes at a personal cost.

In any reorientation of health care toward self-management, in effect a shift from formal institutional care to informal domestic care, there are decisions to be made about how both costs and responsibility will be allocated, and how the skills and resources are to be made available at the point of care. There are limits to the capacity of both health care and social care services to respond to the nature and size of demand. Equally, there are limits to the amounts of extra health work that might be reasonably expected of those whose resources are already constrained due to the many effects of ill-health. Shippee and colleagues, ${ }^{23}$ for example, have developed a 'cumulative complexity' model that takes account of the dynamic interplay between the workload demanded of patients and their capacity to meet those demands, imbalances in which, they suggest, lead to a spiral of increasing management complexity and difficulty. Whilst there may be benefits gained by increased choice and the sense of empowerment and control a care system reoriented to self-management can provide, these may be off-set by the increased time burden and the opportunity costs to other aspects of daily life. The idea of cumulative complexity allows the impact of variations in many areas of a patient's life to be understood as part of what patients, and their health care teams, must manage.

Informed by such a model, research might address different approaches to minimising time and cost burdens, an aspect of May's 'treatment burden', generally, and in relation to specific, and varying, needs and priorities of people with chronic illness and their carers. In this, our findings provide important pointers to health policy and health care system strategy. The specifics of everyday management of chronic illness are affected by the design of the health care system at the micro level. Expectations of self-management need to be developed with discretion and plans tailored to the specific time burdens and capacities associated with different illnesses found in our study, particularly for people with multiple chronic illnesses. For example, our study found that people with COPD spend more time managing their health than people with heart disease.

Solutions could be found at the micro level. For example technical solutions offer value for the day-to-day activities that comprised the greatest time commitment for all the study participants. These solutions include 'time savers' such as blister packs for medications put together by the pharmacist or aids such as home tele-monitoring.

Other solutions come from skill enhancement education programs for conditionrelated knowledge and decision-making skills. Accounts from our earlier qualitative study $^{8}$ suggest that too often people felt 'cast adrift' and uncertain about what course of action they should take. A solution to the substantial blocks of time required for health service consultations, particularly for those people with the heaviest time loads for their illness, would require service providers to schedule activities to minimise wasted time and effort for the patient, rather than scheduling principally to meet the logistical challenges of institutional and professional service provision.

Many of the activities that constitute the majority of the time expenditure, such as taking medications or carrying out treatments, would be difficult or impossible to be done by anyone other than the patient or someone close to them. The nature of this 
time expenditure highlights the importance of seeing the patient and their care in the context not only of their health care, but in terms of the capacity of their communities to support care by picking up other aspects of the management burden and allowing people with increasing chronic illness demands a continued role in their family, social and community activities.

This leads to further consideration of Wagner's ${ }^{4}$ Chronic Care Model, since the role of the network of community-based supports and services that surround the individual and their family has, in Australia at least, received little attention in planning the supports and services needed by the person with chronic illness. These models are being explored by initiatives such as the WISE Initiative (Whole Systems Informing Self-Management Initiative) being explored by a team of researchers at the University of Manchester, ${ }^{7}$ or the Norwegian Coordination Reform. ${ }^{24}$

Our study provides empirical data to underpin an examination of the way patient and carer activity and cost might be factored into the wider system analysis for self-care support, but is far from exhaustive. This suggests that further research might both continue to build understanding of the specific work of chronic illness, as well as to examine what models of care will be able to meet the highly variable needs of patients in supporting their own health.

\section{Conclusion}

This study highlights the complex nature of health care work undertaken by people with chronic illness. It begins to provide information about the scale of the time costs borne by people who are older and sicker, which, for some, amounts to close to a full time job. Such a commitment demands that other activities, many of which might add to life quality, are displaced. Understanding these demands is a necessary step towards better matching of treatment burden with patient capacity.

\section{Acknowledgements}

The authors would like to thank National Seniors Association, Diabetes Australia and The Lung Foundation for their assistance in carrying out this study. In particular, we thank the members of these organisations who completed the survey and our colleagues in the Serious and Continuing Illnesses Policy and Practice Study for their many contributions. We also thank Dr Robin Bunton, Dr Lesley Jones and Dr Jose Valderas for their contribution to the discussion of the findings.

\section{Funding}

This research received funding through NHMRC Program Grant to the Menzies Centre for Health Policy at The University of Sydney and the Australian National University.

\section{References}

1. Department of Health and Ageing. A national health and hospitals network: further investments in Australia's health. Canberra: Commonwealth of Australia, 2010. Contract No. P3-6523.

2. National Health and Hospitals Reform Commission. A healthier future for all Australians: Final Report June 2009. Canberra 2009. Report No. P3-5499.

3. Jowsey T, Jeon Y-H, Dugdale P, et al. Challenges for co-morbid chronic illness care and policy in Australia: a qualitative study. Aust $N Z$ Health Policy 2009; 6(22): 1-8.

4. Wagner E. Chronic disease management: what will it take to improve care for chronic illness? Effect Clin Pract 1998; 1(1): 2-4.

5. Corbin $\mathbf{J}$ and Strauss A. Managing chronic illness: three lines of work. Qual Sociol 1985; 8(3): 224-247.

6. May C, Montori VM and Mair FS. We need minimally disruptive medicine. BMJ 2012; 339(b2803).

7. Rogers A, Vassilev I, Sanders C, et al. Social networks, work and network-based resources for the management of long-term conditions: a framework and study protocol for developing self-care support. Implement Sci 2011; 6(56).

8. Jeon Y-H, Jowsey T, Yen L, et al. Achieving a balanced life in the face of chronic illness. Austr $J$ Primary Health 2010; (16): 66-74. 
9. Ong BN, Jinks C and Morden A. The hard work of self-management: living with chronic knee pain. Int J Qual Stud Health Well-being 2011; 6(3).

10. Russell LB, Ibuka Y and Abraham KG. Healthrelated activities in the American time use survey. Med Care 2007; 45(7): 680-685.

11. Russell LB, Ibuka Y and Carr D. How much time do patients spend on outpatient visits?: the American time use survey. Patient 2008; 1(3): 211-222.

12. Ettner SL, Cadwell BL, Russell LB, et al. Investing time in health: do socio-economically disadvantaged patients spend more or less extra time on diabetes self-care?Health Econ 2009; 18: 645-663

13. Safford MM. Making the most of the time we have. Fam Med Forum 2005; 54(5): 455-456.

14. Russell LB, Dong-Churl S and Safford MM. Time requirements for diabetes self-management: too much for many? J Fam Pract 2005; 54(1): 52-56.

15. Bair MJ, Matthias MS, Nyland KA, et al. Barriers and facilitators to chronic pain self-management: a qualitative study of primary care patients with comorbid musculoskeletal pain and depression. Pain Med 2009; 10(7): 1280-1290.

16. Bittman M, Fast J, Fisher K, et al. Making the invisible visible. The life and time(s) of informal caregivers. In: Folbre N, Bittman M (eds) Family time: the social organization of care. London: Routledge, 2004, pp.69-89.

17. Bittman M, Fisher K, Hill P, et al. The time cost of care. Int J Time Use Res 2005; 2(1): 54-66.

18. Bittman $\mathrm{M}$ and Thomson $\mathrm{C}$. Invisible support: the determinants of time spent in informal care. In: Warburton J, Oppenheimer M (eds) Volunteers \& volunteering. Sydney: Federation Press, 2000, pp.98-112.

19. McKenna K, Liddle J, Brown A, et al. Comparison of time use, role participation and life satisfaction of older people after stroke with a sample without stroke. Austr Occup Therap J 2009; 56(3): 177-188.

20. Dumont S, Jacobs P, Turcotte V, et al.

Measurement challenges of informal caregiving: a novel measurement method applied to a cohort of palliative care patients. Soc Sci Med 2010; 71(10): 1890-1895.

21. Jeon Y-H, Essue B, Jan S, et al. Economic hardship associated with managing chronic illness: a qualitative inquiry. BMC Health Serv Res 2009; 9(1): 182.

22. Fisher K, Gershuny J, Altintas E, et al. Multinational time use study user's guide and documentation. Oxford: Centre for Time Use
Research, 2012. http://www.timeuse.org/mtus/ guide (accessed 8 January 2012).

23. Shippee N, Nilay DS, May CR, et al. Cumulative complexity: a functional, patientcentered model of patient complexity can improve research and practice. J Clin Epidemiol 2012; 65(10): 1041-1051.

24. Heimly V and Hygen J. The Norwegian Coordination Reform and the role of electronic collaboration. Electron J Health Inform 2011; 6(4): e29.

\section{Appendix}

\section{Time questions}

Q47

On most days how much time do you generally spend on each of the following? Sorting your medications Preparing your medications Taking your medications Carrying out treatments Testing or monitoring your health Preparing special foods Taking exercise/stretching

\section{Q48}

In the last month how much time did you spend on each of the following? Shopping for medicines, equipment or disposables, other necessary health items for yourself Shopping for special foods you may need for yourself

Attending rehabilitation programs

Attending health education of selfmanagement programs

Attending support groups such as cancer or diabetes groups

Looking for and reading health information

Q49

In the last month how much time did you spend on each of the following?

Organising appointments for yourself

Organising travel to and from healthrelated appointments

Travelling to and from health-related appointments, including support groups 
Sitting in waiting rooms

With the doctor or other health professional for consultation, advice or treatment

Having blood tests, x-rays or other tests
Having other medical treatments (eg dialysis, chemotherapy, radiotherapy) 